\title{
Erratum to: Oxycodone/Naloxone Prolonged-Release: A Review of Its Use in the Management of Chronic Pain While Counteracting Opioid-Induced Constipation
}

\author{
Celeste B. Burness • Gillian M. Keating
}

Published online: 15 February 2014

(c) Springer International Publishing Switzerland 2014

Erratum to: Drugs

DOI 10.1007/s40265-014-0177-9

Section 4.1.1, Fig. 2b OXN3001 and OXN3006 (bowel) studies: The pre-randomization phase which previously read: "screening $\leq 7$ days", "run-in $\leq 7$ days" and "run-in treatment with OXY IR".

Should read: "screening $\leqq 14$ days", "run-in 7-28 days" and "run-in treatment with OXY PR"

A corrected version of Fig. 2 appears here.

The online version of the original article can be found under doi:10.1007/s40265-014-0177-9. 
A OXN3401 (analgesia) study

PHASE:

PERIOD:
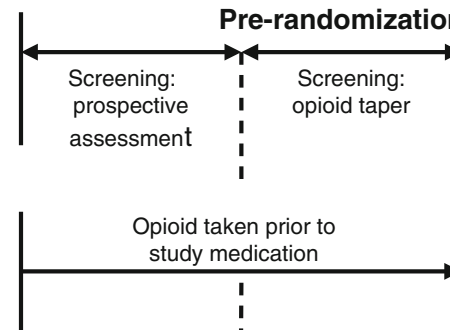

Opioid taken prior to
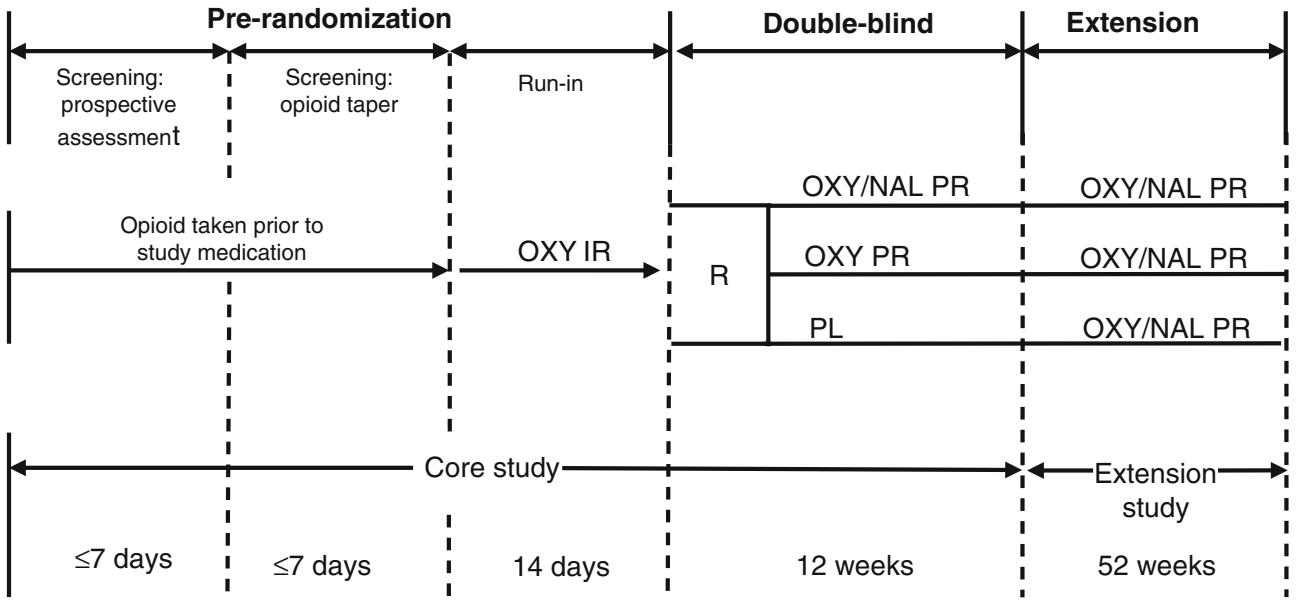

B OXN3001 and OXN3006 (bowel) studies

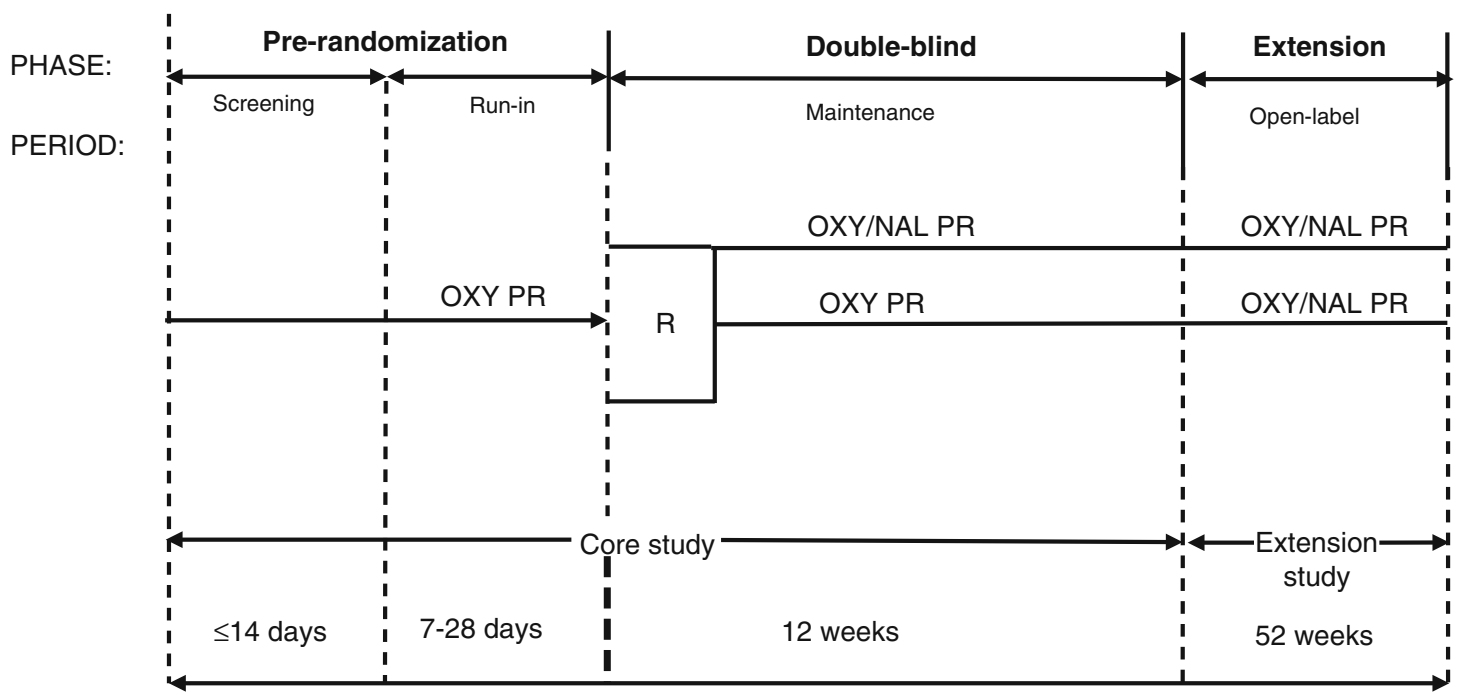

